\title{
Titanium Electrical Resistivity in Hydrogen and Deuterium
}

\author{
A. Pozio, A. Aurora, L. Della Seta, A. Santucci, and S. Tosti
}

Submitted: 18 July 2021 / Revised: 3 December 2021 / Accepted: 11 December 2021 / Published online: 23 February 2022

\begin{abstract}
Electrical resistivity of pure titanium has been measured using the electrochemical impedance spectroscopy technique under an atmosphere of hydrogen and deuterium at $100 \mathrm{kPa}$. In both hydrogen and deuterium, the electrical resistivity presents a linear trend with the temperature by exhibiting a different magnitude between the two isotopes. The obtained results are discussed by taking into account the amount of hydrogen and deuterium uploaded into the metal. XRD analysis and TG-DTA measurements have been conducted in the range $25-450{ }^{\circ} \mathrm{C}$ : the different behavior of titanium with the two gases has been explained by the different isotopes interactions with the sample surface where titanium oxides are supposed to be present. An evident metal embrittlement has been observed only in the presence of hydrogen.
\end{abstract}

Keywords deuterium electrical resistivity, hydrogen, titanium

\section{Introduction}

Starting from the 1950 s, the matter of hydrogen interaction with titanium became of interest because of the damage of some jet engine parts due to the embrittlement caused by hydrogen. In parallel, several research activities were initiated to exploit the characteristic of titanium-hydrogen (and it isotopes) interaction for the storage of tritium as solid metal tritide. In fact, at low temperature, tritium is adsorbed into titanium forming a stable metal tritide from which it can be released only by increasing the temperature of the system of several hundred degrees centigrade (Ref 1). Compared with a traditional gas tank, this way of tritium storage is safer and more cost-effective (Ref 2). In the frame of fusion technology applications, titanium alloys were proposed as suitable structural material for first wall and breeding blanket - two regions facing the plasma chamber-mainly because of their long-term residual radioactivity as well as for other properties (such as strength, cost, corrosion resistance) and the presence of an established processing industry. However, due to the high titanium affinity with hydrogen and the consequent potential hydrogen embrittlement and increased tritium inventory, Ti alloys have been abandoned for these applications in fusion reactors (Ref 3$)$.

The H/Ti interaction is a complex phenomenon: According to literature diagram phase (Ref 4) shown in Fig. 1, three different phases $(\alpha, \beta$ and $\delta$ ) of titanium hydrides are formed depending on the temperature and the hydrogen content. For low hydrogen content, the $\alpha$ phase is dominant. For H/Ti values higher than 0.08 , the $\beta$ phase appears if the temperature is

A. Pozio, A. Aurora, and L. Della Seta, ENEA, C.R. Casaccia, Via Anguillarese 301, S. Maria di Galeria, 00123 Rome, Italy; A. Santucci and S. Tosti, Dipartimento Fusione e Tecnologie per la Sicurezza Nucleare, ENEA, Via E. Fermi 45, 00044 Frascati, Italy. Contact e-mail: alfonso.pozio@enea.it. above $300{ }^{\circ} \mathrm{C}$; if the temperature is below $300{ }^{\circ} \mathrm{C}$, the $\delta$ phase occurs. For higher hydrogen content ( $\mathrm{H} / \mathrm{Ti}$ of about 1.5$)$, the $\beta$ phase begins the conversion into $\delta$ phase, which is fully completed for $\mathrm{H} / \mathrm{Ti}$ higher than 2 . The diagram shows three regions where two phases coexist. At temperature below 300 ${ }^{\circ} \mathrm{C}$, there is the $(\alpha+\delta)$ region, while above $300{ }^{\circ} \mathrm{C}$, depending on the hydrogen content, there are two 2-phase regions: the $(\alpha+$ $\beta)$ and the $(\beta+\delta)(\operatorname{Ref} 5)$.

The preparative of titanium hydrides is well known and usually can be done with a modified Sieverts apparatus. The procedure involves an activation step consisting in a highvacuum heat treatment, followed by absorption at a certain temperature under defined hydrogen gas pressures. As example, Setoyama et al. (Ref 6) prepared titanium hydrides $\mathrm{TiH}_{1.9}$ starting from titanium pellets. Pure titanium pellets were put inside the vacuum chamber, evacuated in UHV down to 1.33 $\mu \mathrm{Pa}$ and annealed at $800{ }^{\circ} \mathrm{C}$ for $10 \mathrm{~h}$. Then, the sample was exposed at $50 \mathrm{kPa}$ hydrogen atmosphere in the temperature range of $400-800{ }^{\circ} \mathrm{C}$. In the absence of isotopic effect, and by applying the same procedure in deuterium, the same uploading should be measured. As example, Wille et al. (Ref 7) and Nagasaka et al. (Ref 8) found that deuterium and tritium atoms dissolve in titanium quite similarly to hydrogen on an atomic basis. That is, the number of deuterium (or tritium) atoms that dissolve in titanium is equal to the number of hydrogen atoms that dissolve in it. According to the authors, no isotope effects have been observed in the experiment performed in the temperature range of $500-800{ }^{\circ} \mathrm{C}$ and $\mathrm{H}_{2}\left(\mathrm{D}_{2}\right)$ pressure between $10^{-2}$ and $1 \mathrm{~Pa}$. A very few amount of $\mathrm{H}$ and $\mathrm{D}$ loaded has been detected. Other authors in similar conditions claim an isotopic effect by observing a solubility ratio between hydrogen and deuterium of 1.20 at constant pressure (Ref 9).

Without any activation procedure, the $\mathrm{H}$ and $\mathrm{D}$ loading values reported in the literature are not always coherent by showing that the method of preparation of TiH and TiD plays a determining role. In other words, experimental measurements are strongly influenced by surface condition (Ref 10): The permeability of the hydrogen isotopes through the oxides commonly present on the top of most metals may vary greatly on particular atomic structure (Ref 11). For many structural materials, the simple surface oxides have caused a reduction in hydrogen isotopes permeation of about one order of magnitude 


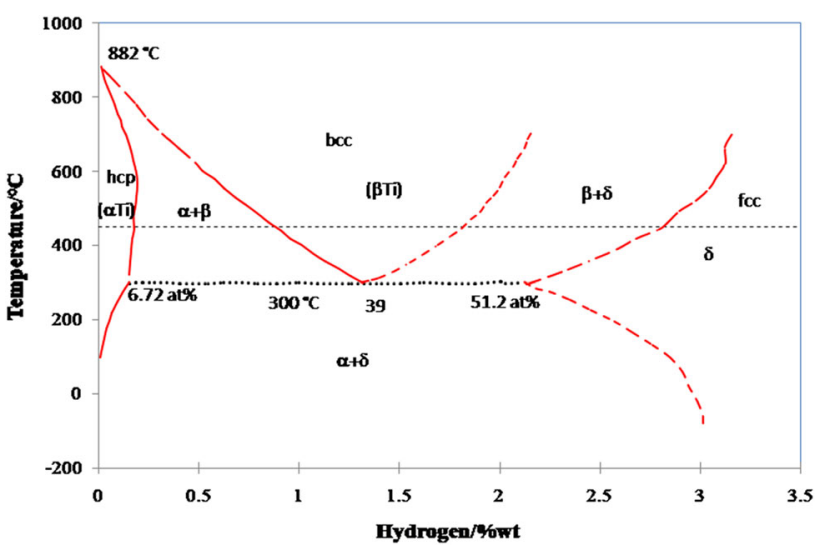

Fig. 1 TiH phase diagram. Reprinted by permission from Springer Nature Customer Service Centre GmbH: Springer Nature, Bulletin of Alloy Phase Diagrams, The H-Ti (Hydrogen-Titanium) System, A. San-Martin and F. D. Manchester, copyright 1987 (Ref 4)

(Ref 12). In addition, activation procedure and size of the titanium sample can also play an important role. Generally, the same procedure has been applied for $\mathrm{TiH}$ and TiD preparation, but an overview of literature shows that TiD preparative is more critical. As example, Hueng et al. (Ref 4) used titanium sponge particles (or titanium metal chips or turnings) to store hydrogen isotope. According to these authors, Ti must be activated in order to absorb isotopes readily. In fact, the activation by heating under vacuum the titanium to about $600{ }^{\circ} \mathrm{C}$ for $2 \mathrm{~h}$ was performed in order to remove volatile impurities and oxides from the titanium surfaces. According to their experience, on such a kind of activated titanium, the hydrogen isotopes are absorbed readily at room temperature $(\mathrm{H}(\mathrm{D}, \mathrm{T}) / \mathrm{Ti}=1.5$ to 2$)$. The hydrogen absorption is an exothermic (heat producing) reaction that releases between 20 and $40 \mathrm{kcal} \mathrm{mol}^{-1}$. About $95 \%$ of the loaded hydrogen was recovered in a reasonable time by increasing the temperature up to $600{ }^{\circ} \mathrm{C}$ under a vacuum of $133 \mathrm{~Pa}$.

Sheng et al. (Ref 13) obtained deuteration of titanium with a pretreatment of the sample in a reaction chamber evacuated to about $10 \mathrm{~Pa}$ and $200-300{ }^{\circ} \mathrm{C}$. Then, the temperature was increased to about $400{ }^{\circ} \mathrm{C}$ and the sample was exposed to a deuterium atmosphere of $50 \mathrm{kPa}$. In this condition, the authors observed that the average $\mathrm{D} / \mathrm{Ti}$ ratio depends on the thickness of Ti foil: For thicknesses lower than $5 \mu \mathrm{m}$, the $\mathrm{D} / \mathrm{Ti}$ atomic ratio can reach a value around 1.2-1.4, while for powder samples the $\mathrm{D} / \mathrm{Ti}$ atomic ratio can reach the value of 1.6. For Ti foil with a thickness of $0.5 \mathrm{~mm}$, the $\mathrm{D} / \mathrm{Ti}$ ratio decreases to about 0.1 . The obtained results suggested that, for such operative pressure, most of deuterium was loaded only near the Ti surface. Burrel et al. (Ref 14) demonstrated that, when a clean titanium film is exposed to deuterium, the latter is readily adsorbed along the entire film to form $\mathrm{TiD}_{2}$ also at low partial pressure. Conversely, it was found that an oxidized Ti film can cause a complete passivation toward the deuterium adsorption reaction. According to these authors, the presence of the oxides decreases the deuterium absorption rate which indeed is completely inhibited when the oxides thickness is greater than 15-20 A. In addition, Briand et al. (Ref 15) have observed that the first condition to saturate $\mathrm{Ti}$ with deuterium by electrolysis in $\mathrm{D}_{2} \mathrm{O}$ solution is to avoid $\mathrm{TiO}_{2}$ contamination of the surface. Their results on $50 \mu \mathrm{m}$ titanium foils showed that without the removal of the $\mathrm{TiO}_{2}$ surface, deuterium was not embedded into titanium.

Starting from a grade 2 CP-Ti bulk samples, Chang et al. (Ref 16) realized a stable $\mathrm{TiD}_{1.91-1.99}$ by gas charging. They uploaded the sample by a treatment in $500 \mathrm{kPa}$ pure $\mathrm{D}_{2}$ atmosphere (purity $99.98 \%$ ) at $600{ }^{\circ} \mathrm{C}$ for $6 \mathrm{~h}$, followed by furnace cooling in $\mathrm{D}_{2}$ atmosphere.

Fernandez et al. (Ref 17) prepared titanium hydride and deuteride samples (250-1000 mg) using a modified Sievertstype apparatus at 350,500 and $800{ }^{\circ} \mathrm{C}$ and $6 \mathrm{kPa}$. Before exposing the titanium to the $\mathrm{H}(\mathrm{D})$ atmosphere, they heated the sample under vacuum at $200{ }^{\circ} \mathrm{C}\left(\mathrm{T}_{1}\right)$ with a heating rate of 20 ${ }^{\circ} \mathrm{C} \min ^{-1}$. They kept the sample at $\mathrm{T}_{1}$ for a certain time, $t_{1}$, that varied between 0 and $17 \mathrm{~h}$. After this pre-treatment, hydrogen was introduced into the system and the author observed that at 500 and $800{ }^{\circ} \mathrm{C}$ it was immediately absorbed. However, at lower temperature $\left(350{ }^{\circ} \mathrm{C}\right)$, the sample started to absorb hydrogen only after a certain activation time $\left(t_{\mathrm{a}}\right)$ spanning from $10 \mathrm{~min}$ to $4 \mathrm{~h}$ depending on $t_{1}$. No significant isotopic differences were found during the absorption process, and $[\mathrm{H}(\mathrm{D})] /[\mathrm{Ti}] 1.97$ was obtained at $350{ }^{\circ} \mathrm{C}$.

Anzorena et al. (Ref 18$)$ obtained a Ti layer $(2 \mu \mathrm{m})$ by PVD on $\mathrm{Cu}$ or $\mathrm{Al}$ substrate at a pressure between 4 and $8 \mathrm{mPa}$ and a deposition rate between 20 and $25 \AA /$ s. By maintaining the vacuum inside the deposition chamber, the layer was irradiated with $\mathrm{D}_{2}$ at $100 \mathrm{kPa}$ and $200{ }^{\circ} \mathrm{C}$ in about $0.5-2 \mathrm{~h}$ to form $\mathrm{TiD}_{2}$. With a similar process, also Monnin et al. (Ref 19) obtained $\mathrm{TiD}_{1.43}$ irradiating Ti layer or powder with $\mathrm{D}_{2}$ at $20-0.95 \mathrm{kPa}$ and $420{ }^{\circ} \mathrm{C}$ in about $0.6 \mathrm{~h}$. These authors observed that morphology and presence of superficial oxide are the key parameters for the deuterium absorption.

Lastly, Yamanaka et al. (Ref 20) investigated the effect of the oxygen addition in titanium on the hydrogen isotopes solubility. Their results on pure titanium and titanium-oxygen alloys $(10-30 \% \mathrm{O})$ show an $\mathrm{H}_{2}$ solubility higher than $\mathrm{D}_{2}$. This fact is explained in view of the blocking effect due the soluted oxygen. The authors suggested that the reduction in solubility of hydrogen isotopes by dissolved oxygen is attributable to the more repulsive interaction between hydrogen isotopes and oxygen within titanium.

Summarizing, the examination of literature illustrates that: (1) preparation of Ti sample for isotope charging should require a pre-treatment heating in vacuum (UHV) to degas it and to eliminate the extremely stable and thin oxide layer (Ref 21$)$, which can interfere in isotope experiments; (2) the characteristics of sample can play a determining role (powder, shavings or thin film, layers can absorb deuterium in different amount); (3) to obtain reproducible results with bulk samples particular conditions must be used, corresponding to high pressure and temperature as done in the most cases. Due to dispersion of data, it is very difficult to understand if the different results present in the literature in charging $\mathrm{D} / \mathrm{Ti}$ are due to the isotopic effect or to the preparative method. If we compare only those works in which a specific activation procedure on the titanium was followed, the difference in $\mathrm{H}(\mathrm{D}) / \mathrm{M}$ isotope ratio is very limited. On the opposite, in the presence of oxidized titanium surface, the differences seem to be more relevant (Table 1).

In this study, we decide to evaluate the isotope effects without any defined titanium pre-treatment in order to verify it in normal operative condition. Therefore, commercial titanium samples without any treatment have been used. This means that the surface is characterized by the presence of a thin, amorphous, nonstoichiometric $\mathrm{TiO}_{2}$ protective layer $(10 \mathrm{~nm})$ 
Table 1 Ti deuteration in the literature

\begin{tabular}{|c|c|c|c|c|}
\hline Sample & Activation & $D_{2}$ absorption & $\mathbf{D} / \mathbf{T i}$ & Ref. \\
\hline Ti sponge & $600^{\circ} \mathrm{C} 2 \mathrm{~h}$ vacuum & $25^{\circ} \mathrm{C}$ & $1.5-2$ & 4 \\
\hline Ti foil $0.5 \mathrm{~mm}$ & $200-300{ }^{\circ} \mathrm{C} 10 \mathrm{~Pa}$ & $400^{\circ} \mathrm{C}-50 \mathrm{kPa}$ & 0.1 & 13 \\
\hline Ti powder & $200-300{ }^{\circ} \mathrm{C} 10 \mathrm{~Pa}$ & $400^{\circ} \mathrm{C}-50 \mathrm{kPa}$ & 1.6 & 13 \\
\hline $\mathrm{Ti} / \mathrm{TiO}_{2}$ film/gold & Not necessary & $1.33 \mathrm{mPa}$ & 0 & 14 \\
\hline $\mathrm{Ti} / \mathrm{TiO}_{2}$ foil $50 \mu \mathrm{m}$ & $\ldots$ & Electrolysis in $\mathrm{D}_{2} \mathrm{O}$ & 0 & 15 \\
\hline Ti bulk & Unspecified & $600{ }^{\circ} \mathrm{C}-500 \mathrm{kPa}$ & 1.5 & 16 \\
\hline Ti sponge & $200{ }^{\circ} \mathrm{C} 17 \mathrm{~h}$ vacuum & $350{ }^{\circ} \mathrm{C}-600 \mathrm{kPa}$ & 1.96 & 17 \\
\hline $\mathrm{Ti} / \mathrm{Cu}$ layer $2 \mu \mathrm{m}$ & PVD condition & $200{ }^{\circ} \mathrm{C}-100 \mathrm{kPa}$ & 1.9 & 18 \\
\hline Ti powder & Unspecified & $420{ }^{\circ} \mathrm{C}-100 \mathrm{kPa}$ & 1.64 & 19 \\
\hline Ti film/Cu mm & PVD condition & $420{ }^{\circ} \mathrm{C}-100 \mathrm{kPa}$ & 1.43 & 19 \\
\hline Ti sheet $1 \mathrm{~mm}$ & Unspecified & $600-850{ }^{\circ} \mathrm{C}-100 \mathrm{kPa}$ & $1.0-1.2$ & 19 \\
\hline
\end{tabular}

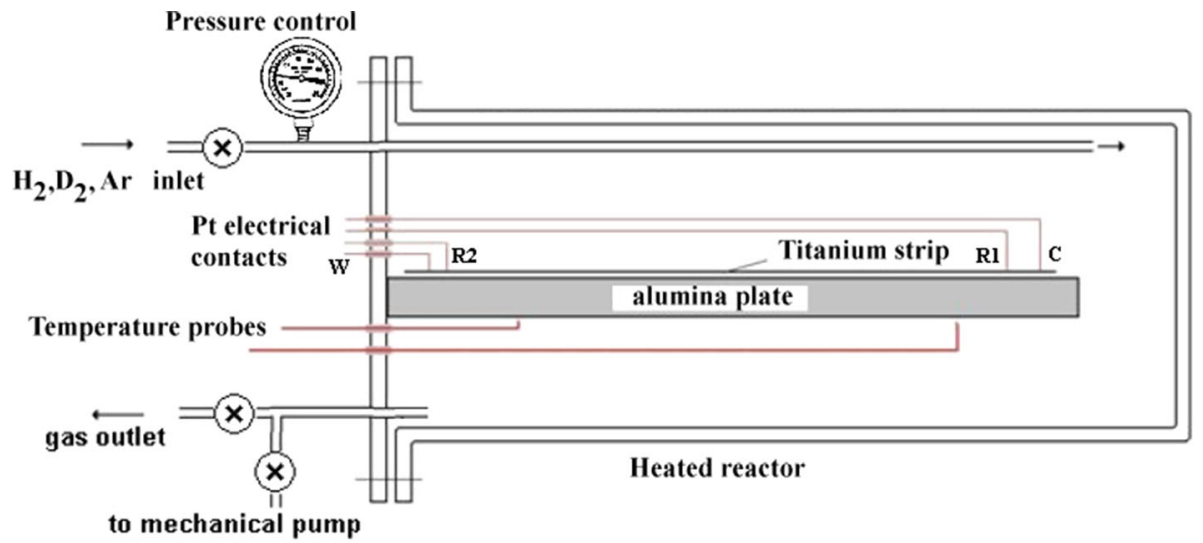

Fig. 2 Experimental apparatus

that is spontaneously formed due to the aerated environment exposure (Ref 22-24). In this work, we measured the resistivity versus temperature in hydrogen and deuterium. The loading of isotopes was analyzed by means of thermogravimetry and XRD in order to evaluate the $\mathrm{H} /(\mathrm{D}) / \mathrm{M}$ ratio. Not surprisingly, the results showed a great difference among hydrogen and deuterium. Some hypotheses were introduced to explain the observed differences.

\section{Experimental Methods}

Ac impedance was used to measure the resistivity in the two-electrode mode using a Solartron 1260 frequency response analyzer (Schlumberger). The impedance data were recorded at a constant frequency of $10 \mathrm{~Hz}$ with a $5 \mathrm{~s} / \mathrm{step}$ and maximum perturbation amplitude of $0.5 \mathrm{~mA}$. The titanium sample (Aldrich) had the shape of a thin strip with dimensions of $141.0 \mathrm{~mm}$ length, $4.4 \mathrm{~mm}$ width and $51 \mu \mathrm{m}$ of thickness. The ends of the foil were connected to four parallel platinum electrical contacts, and the sample was placed inside a stainlesssteel vessel (Ref 25). The AC circuit of the sample consists of a pure ohmic resistance only and shows negligible values of inductance or capacitance in the impedance. So, with this configuration, the length $(l)$ among the voltage measurement points over the Ti strip was $137.5 \mathrm{~mm}$ and, from the impedance measurements along the plane (tangential direction), it was possible to assess the resistivity according to the following formula:

$\rho=\frac{R_{\Omega} \times A}{l}$

where $\rho, l, R_{\Omega}$ and $A$ denote the resistivity, the distance between the probe, the measured resistance and the cross-sectional area of the Ti sample. Particularly, the area $A$ was obtained from the product of the thickness of the Ti strip $(r)$ and its width $(h)$.

As shown in Fig. 2, the gastight stainless-steel module has an electrical heater and two temperature probes and it allows the $\mathrm{H}_{2}, \mathrm{D}_{2}$ and $\mathrm{Ar}$ inlet and outlet. The module is thermally insulated and of small size to guarantee a homogeneous temperature for the entire volume.

The titanium strip was obtained by cold rolling down to 51 $\mu \mathrm{m}$ a commercial foil (Aldrich) of $0.25 \mathrm{~mm}$ thick with a purity of $99.7 \%$ on a metal basis. The experiments focused on the study of the electrical resistivity behavior of hydrogenated and deuterated titanium by varying the temperature in the range 25 $450{ }^{\circ} \mathrm{C}$ at the pressure of $100 \mathrm{kPa}$. Temperature and resistivity were recorded continuously during the tests. Heating in H, D 


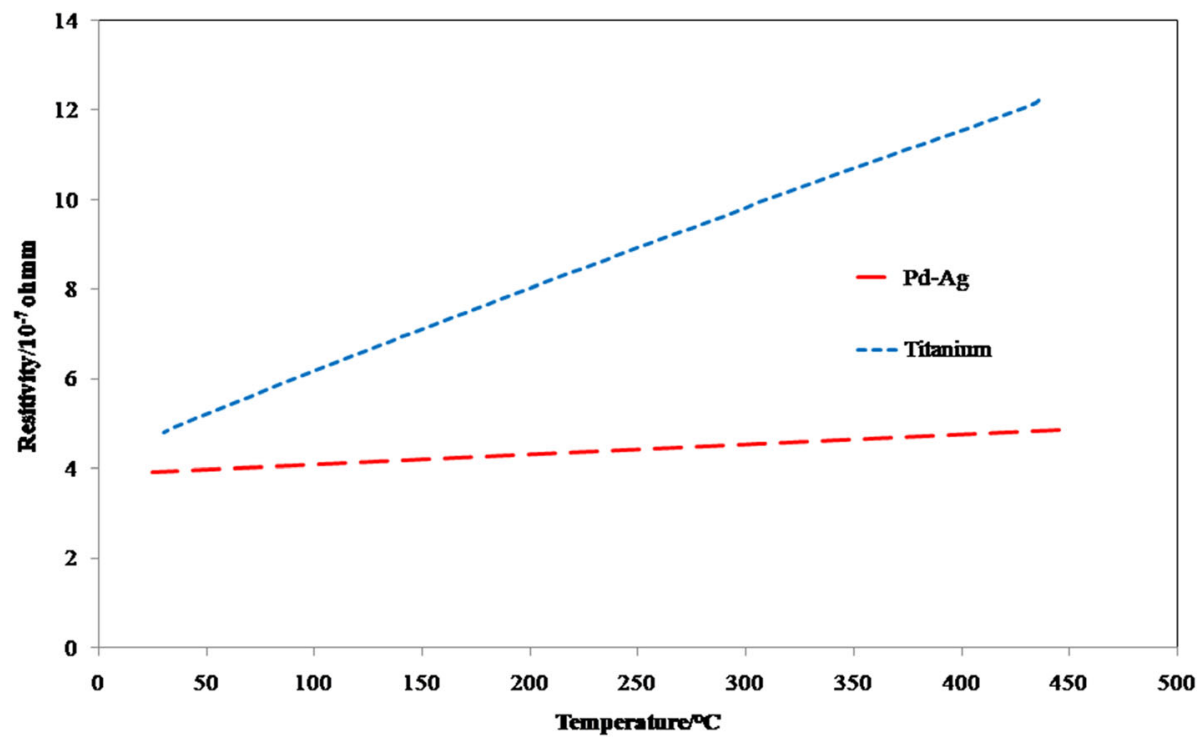

Fig. 3 Final resistivity vs. temperature of titanium and Pd-Ag in argon

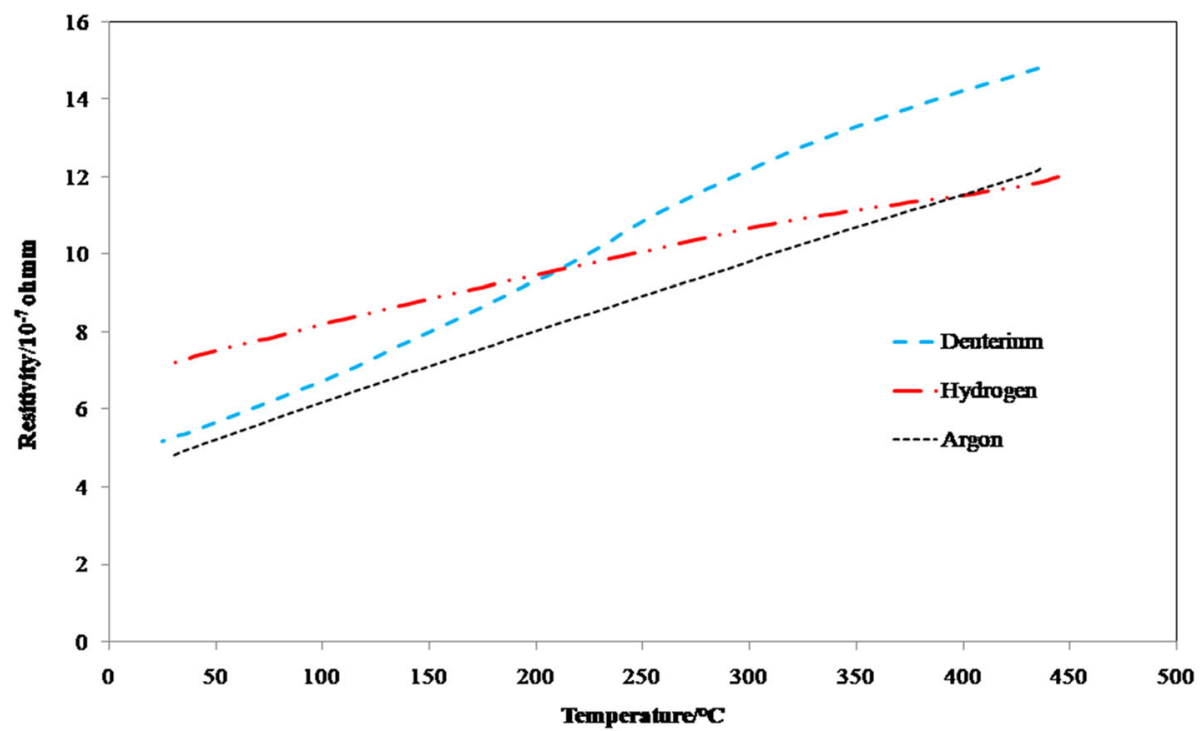

Fig. 4 Final resistivity vs. temperature of titanium after several cycles in $\mathrm{H}_{2}, \mathrm{D}_{2}$. Starting measurement in Ar is reported as reference

and argon atmosphere has been performed at $5{ }^{\circ} \mathrm{C} \min ^{-1}$. In addition, simultaneous thermogravimetric (TG-DTA) curves have been registered using the thermal analysis equipment TA Instruments Q600 system analyzer. The temperature was calibrated using the nickel Curie point as reference. For this specific set of measurements, the DTA baseline and TGA weight calibration have been carried out in Ar. Samples of about $8 \mathrm{mg}$ weight, in the shape of a pile of $5 \mathrm{Ti}$ squared laminas, were placed in high-purity alumina crucible and tested with a thermal profile consisting in an initial ramp from room temperature to $450{ }^{\circ} \mathrm{C}$ at a heating rate of $5^{\circ} \mathrm{C} \mathrm{min}-1$ followed by an isotherm at $450{ }^{\circ} \mathrm{C}$. The measurements have been stopped once the stabilization of the weight has been reached. The measurement has been performed in an argon/hydrogen or argon/deuterium gas mixture in the ratio $\mathrm{Ar} / \mathrm{H}_{2}\left(\right.$ or $\left.\mathrm{D}_{2}\right)$ of $9: 1$. The total gas flow rate has been of $100 \mathrm{~mL} \mathrm{~min}^{-1}$.

\section{Results and Discussion}

\subsection{Electrical Resistivity Versus Temperature}

A linear equation usually describes the relationship between the electrical resistance of metals $\left(\rho_{T}\right)$ and temperature (Ref 26):

$\rho_{T}=\rho^{\circ}\left[1+\alpha\left(T-T^{\circ}\right)\right]$

where $T$ is the measured temperature, $T^{\circ}$ is the reference temperature (normally ambient), $\rho^{\circ}$ is the resistivity at the reference temperature $T^{\circ}$, and $\alpha$ is the so-called thermal coefficient (the change in resistivity per unit of temperature). The $\alpha$ coefficient depends on the type of metal and, for a reduced temperature range, can be assumed constant. Equation 2 is valid for non-hydrogenated material. Particularly in 
argon, the resistivity behavior versus temperature of the titanium sample foil was almost linear in the range $0-450{ }^{\circ} \mathrm{C}$, the $\alpha$ value was $3.7 \times 10^{-3}{ }^{\circ} \mathrm{C}^{-1}$, while the resistivity, $\rho^{\circ}$, at 25 ${ }^{\circ} \mathrm{C}$ was $4.8 \times 10^{-7} \Omega \mathrm{m}$. These measured values are a bit higher than those reported in the literature for pure Ti metal $(3.2 \times$ $10^{-3}{ }^{\circ} \mathrm{C}^{-1}$ and $\left.4.4 \times 10^{-7} \Omega \mathrm{m}\right)(\operatorname{Ref} 27)$. It is known that a titanium sheet exposed to the air is covered with a thin and compact layer of titanium oxide (Ref 28). In our case, since no pre-treatment was done on the sample, the measured resistivity

Table 2 Change of resistivity $\left(10^{-7} \Omega \mathrm{hm} \mathrm{m}\right)$ cycling 25 $450{ }^{\circ} \mathrm{C}$ in $\mathrm{H}_{2}$ and $\mathrm{D}_{2}$

\begin{tabular}{|c|c|c|c|c|c|c|}
\hline \multirow[b]{2}{*}{ Cycle } & \multicolumn{2}{|c|}{$\rho$ in Hydrogen } & \multicolumn{2}{|c|}{$\rho$ in Deuterium } & \multicolumn{2}{|c|}{$\rho$ in Argon } \\
\hline & $25^{\circ} \mathrm{C}$ & $450^{\circ} \mathrm{C}$ & $25^{\circ} \mathrm{C}$ & $450^{\circ} \mathrm{C}$ & $25^{\circ} \mathrm{C}$ & $450{ }^{\circ} \mathrm{C}$ \\
\hline I & 4.4 & 12.6 & 4.6 & 12.9 & 4.4 & 11.6 \\
\hline II & 5.1 & 13.0 & 4.8 & 13.8 & " & $\prime \prime$ \\
\hline III & 5.9 & 10.9 & 5.2 & 14.8 & $"$ & $" \prime$ \\
\hline IV & 5.9 & 10.7 & 5.2 & 14.8 & " & $\prime \prime$ \\
\hline V & 7.1 & 12.1 & & & " & $" \prime$ \\
\hline VI & 7.1 & 12.1 & & & $"$ & $" \prime$ \\
\hline
\end{tabular}

should be affected by the presence of this layer. In confirmation of this hypothesis, Ames et al. (Ref 29) observed that low oxidation of titanium sample increases the resistivity $\rho_{25}{ }^{\circ} \mathrm{C}$ at $4.7 \times 10^{-7} \Omega \mathrm{m}$. This fact explains the small difference among the measured values and the ones reported in the literature.

Figure 3 shows the trend of resistivity versus $T$ compared to that of a 21 wt.\% Pd-Ag sheet, system which has been considered here as a reference for its capacity of absorbing hydrogen reversibly (Ref 30 ). As shown, at $25{ }^{\circ} \mathrm{C}$, the starting resistivity values are very similar, but, by raising the temperature, titanium, unlike the $\mathrm{Pd}-\mathrm{Ag}$ alloy, shows an increase in resistivity compared to the initial value of about 2.5 times against 1.2. This difference is explained by considering that the $\alpha$ value of the $\mathrm{Pd}-\mathrm{Ag}$ alloy is approximately seven times lower than that of titanium.

The hydrogen treatment consisting in several heatingcooling cycles produces an irreversible change in the titanium (Fig. 4) that undergoes a structural change to titanium hydride. The resistivity trend remains linear, but the slope, or the thermal coefficient $\alpha$, is reduced to about $1.5 \times 10^{-3}{ }^{\circ} \mathrm{C}^{-1}$ and, at the same time, the resistivity at $25^{\circ} \mathrm{C}$ is increased up to $7.1 \times 10^{-7}$ $\Omega \mathrm{m}$. This trend is similar to that measured by Ito et al. (Ref 31$)$ on $\mathrm{TiH}_{1.75}\left(1.7 \times 10^{-3}{ }^{\circ} \mathrm{C}^{-1}\right.$ and $\left.7.4 \times 10^{-7} \Omega \mathrm{m}\right)$ who observed that the resistivity of this hydride ( $\delta$ phase) is independent from the hydrogen content. Our material reaches a
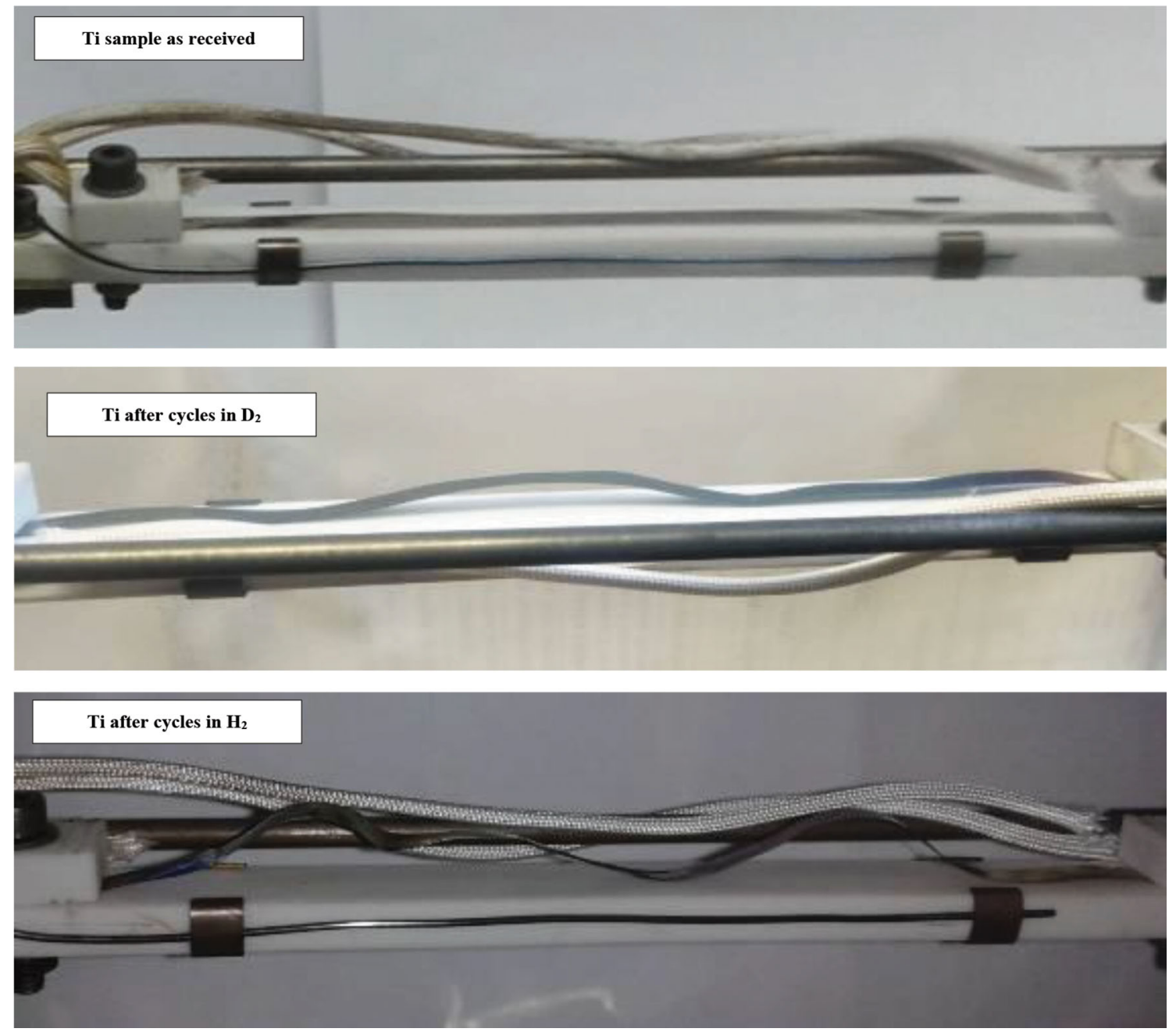

Fig. 5 Titanium sheet sample, as inserted (top), after $\mathrm{D}_{2}$ (middle) and $\mathrm{H}_{2}$ (bottom) resistivity measurements 

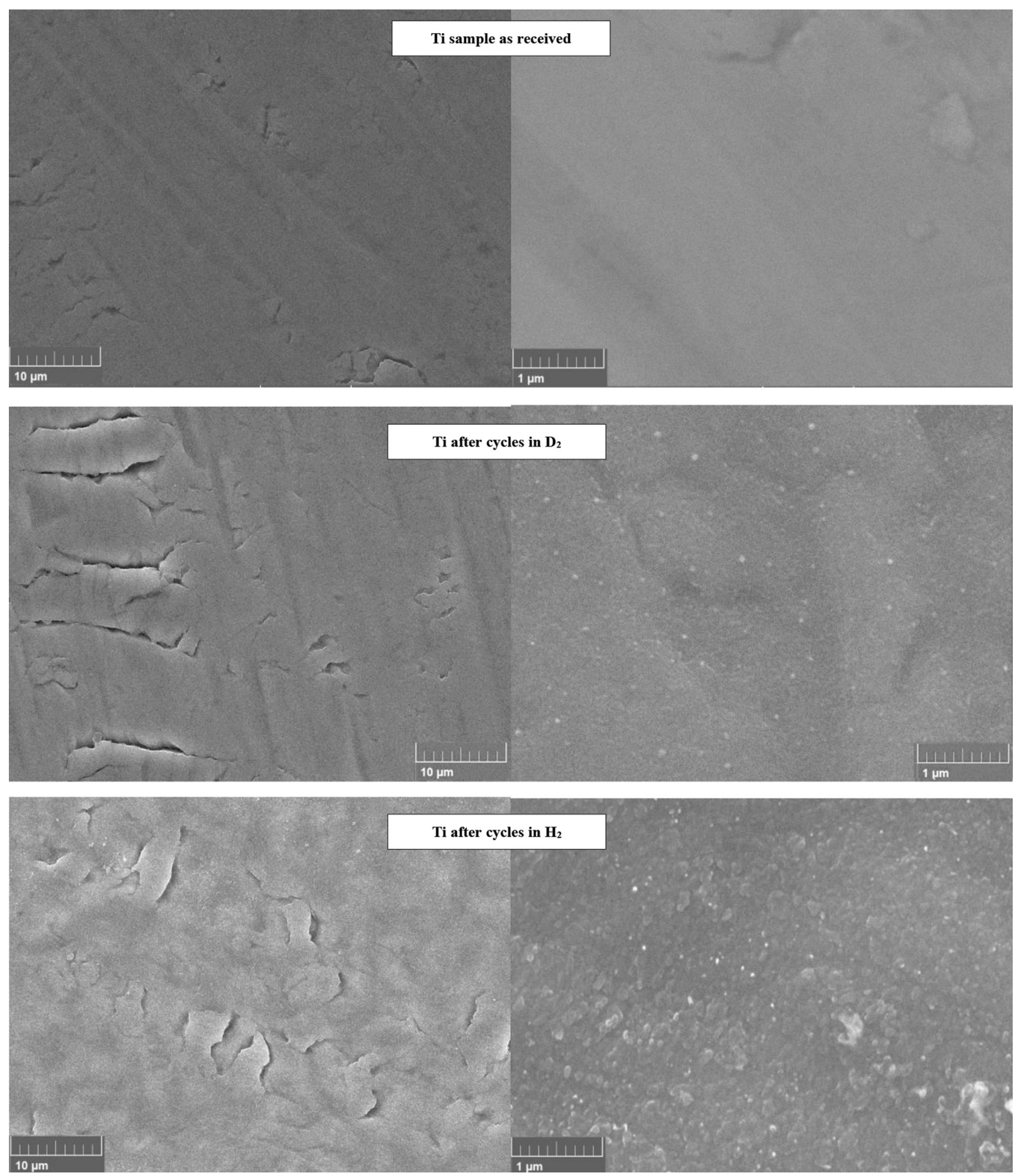

Fig. 6 SEM images of titanium sheet sample, as inserted (top), after $\mathrm{D}_{2}$ (middle) and $\mathrm{H}_{2}$ (bottom) resistivity measurements

condition of stability in only 5-6 heating/cooling cycles and no longer undergoes any changes by thermally treating it either in argon or in air (Table 2). The greater resistivity of $\mathrm{TiH}$ compared to $\mathrm{Ti}$ at room temperature can be due to the formation of the metal-hydrogen bond that removes electrons from the electrical conduction mechanism. On the other hand, as the temperature increases the thermal vibration of the $\mathrm{TiH}$ lattice (caused by electrons being scattered by phonons) increases less than that of the titanium lattice. Such a behavior facilitates the movement of the conduction electrons, and, consequently, the resistivity of the two structures converges toward similar values.

The deuterium treatment of a new titanium sample shows a different behavior. The material reaches a stable condition in 
just 2-3 cycles (Table 2). Although also in this case the trend of the resistivity remains linear $\left(r^{2}=0.997\right)$, the behavior is opposite, the thermal coefficient $\alpha$ increases up to about $4.9 \times$ $10^{-3}{ }^{\circ} \mathrm{C}^{-1}$, and the resistivity at $25^{\circ} \mathrm{C}$ is $5.2 \times 10^{-7} \Omega \mathrm{m}$. Also in this case, the greater resistivity of TiD compared to titanium at room temperature can be due to the formation of the metalhydrogen bond that removes electrons from the electrical conduction mechanism, but being deuterium in small quantities (see the following "Sect. 3"), this increase has less effective. As the temperature increases due to the higher thermal coefficient, the resistivity in deuterium grows faster so that at about $230{ }^{\circ} \mathrm{C}$ it overcomes that of the sample in hydrogen. To explain this behavior, we can suppose that in this case, by increasing the temperature, the thermal vibration of the deuterium-modified structure increases more than that of the original titanium lattice, so limiting the electrical conduction mechanism.

As a result, at high temperatures the resistivity of the material is lower for the hydrogenated Ti (about $12.0 \times 10^{-7} \Omega$ $\mathrm{m})$ and higher for the deuterated one $\left(14.8 \times 10^{-7} \Omega \mathrm{m}\right)$.

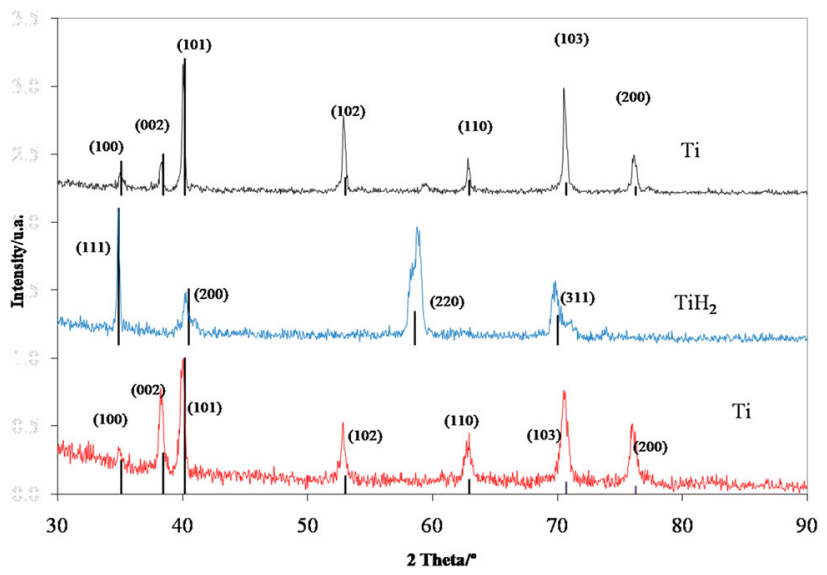

Fig. 7 XRD of original titanium sample (bottom), after resistivity measurements in $\mathrm{H}_{2}$ (middle) and in $\mathrm{D}_{2}$ (top)
The analysis of samples treated in $\mathrm{H}_{2}$ and $\mathrm{D}_{2}$ extracted from the reactor shows different macroscopic and morphological characteristics that can help in the comprehension of the results about the electrical resistivity. After the hydrogen treatment, the foil has undergone an expansion along its length of about $13.5 \%$ and it appears dark and friable, breaking into small fragments at the slightest mechanical stress. The behavior after treatment in deuterium is different, showing a lower dilation $(6 \%)$ and maintaining the same mechanical consistency and metallic aspect (Fig. 5). SEM images (Fig. 6) evidenced the change in structure after treating in hydrogen isotopes with respect to the original sample. Initially, titanium surface appears smooth and without any roughness. Cracks due to cold rolling are evident in the low-magnification images (left). After the treatment in deuterium, small bumps on the Ti appear. Instead, after treatment in hydrogen, the titanium surface appears full of bumps like bubbles and wrinkled.

The XRD measurements (Fig. 7) clarify the observed differences. In $\mathrm{H}_{2}$, a stable hydride is formed very similar to $\mathrm{TiH}_{2}$ (Ref 32, 33), while in the sample treated in deuterium the spectral lines are the same as for titanium (Ref 34), i.e., the equivalent TiD does not appear, except for a slight hint highlighted by the peak (202) at 2 theta equal to about $60^{\circ}$.

The gravimetric measurements (Fig. 8) provide further details on the two systems analyzed. The thermogravimetric analysis (TGA) indicates the degree of saturation in the metal of the two gases subjected to the heat treatment. TGA is performed under the same thermal conditions used for resistance measurement, by increasing the temperature of the sample in a hydrogen or deuterium atmosphere at $5{ }^{\circ} \mathrm{C} \mathrm{min}{ }^{-1}$, i.e., the final temperature $\left(450{ }^{\circ} \mathrm{C}\right)$ is reached in the first $1.5 \mathrm{~h}$, and maintaining this temperature up to the weight stabilization. The titanium in hydrogen gas increases its weight of approximately equal to $4 \mathrm{wt} . \%$, and the stabilization is reached in approx. $30 \mathrm{~h}$, resulting already almost complete after $15 \mathrm{~h}$ at $450{ }^{\circ} \mathrm{C}$. This result fits well with the behavior of the resistivity measurements that exhibited the achievement of stable conditions during the 5th-6th cycle (i.e., after approximately the same time). During weight gain in the first $15 \mathrm{~h}$, the presence of derivative peaks corresponding to exothermic reactions prob-

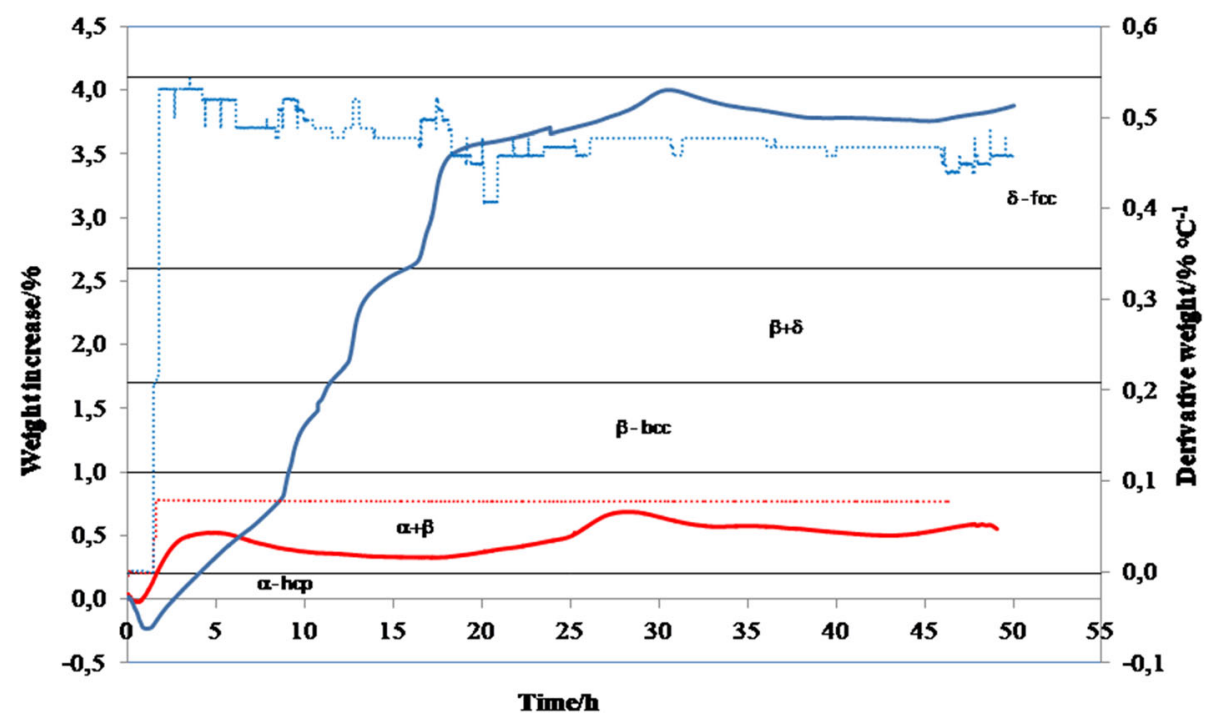

Fig. 8 TG of titanium sample in $\mathrm{H}_{2}(-)$ and $\mathrm{D}_{2}(-)$ and the relative derivative weight in $\mathrm{H}_{2}$ (blue dashed line) and in $\mathrm{D}_{2}$ (red dashed line) at $450{ }^{\circ} \mathrm{C}$ (Color figure online) 
ably related to the formation of $\mathrm{TiH}$ bonds is clearly observed. The weight increase of 4 wt. $\%$ corresponds to a loading of two hydrogen atoms per $\mathrm{Ti}$ atom $\left(\mathrm{TiH}_{2}\right)$ confirming the XRD measurements results. The metal dihydride $\mathrm{TiH}_{2}$ presents the fluorite structure $\left(\mathrm{CaF}_{2}\right)$ at this temperature with the $\mathrm{H}$ ions occupying the eight tetrahedral interstitial sites, whereas Ti ions occupy the regular sites of a face-centered cubic (FCC) structure (Ref 35). On the other hand, the weight increase of titanium in deuterium is only 0.5 wt. $\%$ corresponding to a loading of just 0.1 deuterium atoms per titanium atom $\left(\mathrm{TiD}_{0.1}\right)$, reaching this value in only $4 \mathrm{~h}$ (i.e., only two cycles). In this case, there is no evidence of the presence of derivative peaks in the XRD measurements.

The experimental results evidenced that commercial titanium with thin oxide passivating layers did not absorb deuterium in its structure. We can give an explanation of these phenomena by considering the absorption mechanism in the presence of an oxide layer (Ref 21). The hydride/deuteride formation is strictly related to the different equilibrium of $\mathrm{H}$ and $\mathrm{D}$ with the oxide layer. In order to reach the Ti metal, hydrogen or deuterium should enter the structure of titanium oxide forming hydroxide and then further migrate to reach the metal interface. The hydrogen/deuterium must diffuse through the titanium dioxide film and then must be absorbed at the titanium film interface following the equation:

$$
\begin{aligned}
& \mathrm{TiO}_{2}+1 / 2 \mathrm{H}_{2} \rightarrow \mathrm{TiOOH}+\mathrm{Ti} \rightarrow \mathrm{TiH}+\mathrm{TiO}_{2} \\
& \mathrm{TiO}_{2}+1 / 2 \mathrm{D}_{2} \rightarrow \mathrm{TiOOD}+\mathrm{Ti} \rightarrow \mathrm{TiD}+\mathrm{TiO}_{2}
\end{aligned}
$$

Concerning the interaction between the $\mathrm{TiO}_{2}$ and the two isotopes, differences can occur either in the diffusion along the titanium oxide or in the adsorption on the $\mathrm{TiO}_{2} / \mathrm{Ti}$ interface. The results suggest that, in the case of $\mathrm{D}$, such phenomena are slower than in the case of $\mathrm{H}$.

From physical point of view, it is well known that the oxygen forms a slightly stronger bond to deuterium with respect to the hydrogen because the larger mass of deuterium results in a lower zero-point energy (Ref 36), a quantum mechanical effect analogous to the kinetic isotope effect. So, we can hypothesize that the main difference is due to this interaction. Clearly, any activation process or other similar treatment, destroying the passivation layer, may eliminate this effect.

\section{Conclusion}

In essence, it appears that the uploading into metal of the two hydrogen isotopes, $\mathrm{H}$ and $\mathrm{D}$, exhibits a totally different behavior when a commercial titanium is used without any pretreatment. The hydrogen penetrates the titanium lattice by modifying the composition of the metal with the formation of stable hydrides that irreversibly affect the mechanical characteristics and reduce the thermal coefficient. Deuterium penetrates to an extremely low extent, failing to form stable hydrides but just enough to cause an increase in the thermal coefficient of the electrical resistivity.

The explanation of the different behavior could be attributed to the presence of a thin passivation layer onto the surface that acts as a barrier, especially for the deuterium.
This work highlights the role played by the status of the Ti surface in the absorption mechanisms of the hydrogen isotopes that, in turn, can affect the chemical-physical properties of the hydrogenated (deuterated) metal. These preliminary results are expected to improve the knowledge needed to define the material pretreatments to be adopted in the application of Ti and its alloys in the processes of separation and storage of hydrogen and its isotopes.

\section{Open Access}

This article is licensed under a Creative Commons Attribution 4.0 International License, which permits use, sharing, adaptation, distribution and reproduction in any medium or format, as long as you give appropriate credit to the original author(s) and the source, provide a link to the Creative Commons licence, and indicate if changes were made. The images or other third party material in this article are included in the article's Creative Commons licence, unless indicated otherwise in a credit line to the material. If material is not included in the article's Creative Commons licence and your intended use is not permitted by statutory regulation or exceeds the permitted use, you will need to obtain permission directly from the copyright holder. To view a copy of this licence, visit http://creativecommons.org/licenses/by/4.0/.

\section{References}

1. E.I. Ionete, K. Dylst, C.C. Gheorghe, S.I. Stefan, M.B. Florian, and W. Broeckx, Desorption of Protium and Deuterium from Different Types of Titanium Beds, Fusion Eng. Des., 2017, 116, p 61-65.

2. T. Motyka, Hydrides for Processing and Storing Tritium, Proceedings of the Savannah River Site 50th Anniversary, 2000, p 187-195

3. J.W. Davis and W.L. Smith, The Impact of Hydrogen in a Fusion Reactor Environment on Titanium Alloys, J. Nucl. Mater., 1979, 85(86), p 298-300.

4. A. San-Martin and F.D. Manchester, The H-Ti (Hydrogen-Titanium) System, Bull. Alloy Phase Diagr., 1987, 8(1), p 30-41.

5. L.K. Hueng, Titanium for Long-Term Tritium Storage, Westinghouse Technical Report, WSRC-TR-94-0596, 1994

6. D. Setoyama, J. Matsunaga, M. Ito, H. Muta, K. Kurosaki, M. Uno, and S. Yamanaka, Thermal Properties of Titanium Hydrides, J. Nucl. Mater., 2005, 344, p 298-300.

7. J.W. Wille and J.W. Davis, Hydrogen in Titanium Alloys, DOE Technical Report, DE-AC02-77ET 52039, 1981

8. M. Nagasaka and T. Yamashina, Solubility of Hydrogen and Deuterium in Titanium and Zirconium under Very Low Pressure, J. Less-Common Met., 1976, 45, p 53-62.

9. K. Watanabe, Equilibrium Pressures of Hydrogen and Deuterium Dissolved in Titanium, Zirconium and Hafnium at Low Concentrations, J. Nucl. Mater., 1985, 136, p 1-5.

10. R.A. Causey, R.A. Karnesky, and C. San Marchi, Tritium Barriers and Tritium Diffusion in Fusion Reactors, Comprehensive Nuclear Materials. R.J. Konings, R. Stoller Ed., Elsevier, Amsterdam, 2012, p 511549

11. V. Neemanic, Hydrogen Permeation Barriers: Basic Requirements, Materials Selection, Deposition Methods, and Quality Evaluation, Nucl. Mater. Energy, 2019, 19, p 451-457.

12. G.W. Hollenberg, E.P. Simonen, A. Terlain, and G. Kalinin, Tritium/ Hydrogen Barrier Development, Third International Symposium on Fusion Nuclear Technology, June 27-July 1, Los Angeles, California, 1994

13. J.S. Sheng, L.J. Huai, W.J. Qing, H. Ming, W.S. Yong, Z.H. Tao, Y.S. $\mathrm{He}$, and Z.Y. Gang, Measurement of Anomalous Nuclear Reaction in Deuterium-Loaded Metal, Chin. Phys. B, 2009, 18(4), p 1674-1056.

14. M.C. Burrell and N.R. Armstrong, Deuterium Uptake in Titanium Thin Films: $\mathrm{t}$ ssc00621 the Effect of Oxide, and the Metal ( $\mathrm{Ti}$ and $\mathrm{Fe}$ ) Overlayers, Surf. Sci., 1985, 160(1), p 235-252. 
15. J.P. Briand, G. Ban, M. Froment, M. Keddam, and F. Abel, Cold Fusion Rates in Titanium Foils, Phys. Lett. A, 1990, 145(4), p 188-191.

16. Y.H. Chang, I. Mouton, L. Stephenson, M. Ashton, G.K. Zhang, A. Szczpaniak, W.J. Lu, D. Ponge, D. Raabe, and B. Gault, Quantification of Solute Deuterium in Titanium Deuteride by Atom Probe Tomography with Both Laser Pulsing and High-Voltage Pulsing: Influence of the Surface Electric Field, New J. Phys., 2019, 21, p 053025.

17. J.F. Fernandez, F. Cuevas, M. Alguerò, and C. Sanchez, Influence of the Preparation Conditions of Titanium Hydride and Deuteride $\mathrm{TiH}_{x}\left(\mathrm{D}_{x}\right)(X \sim 2.00)$ on the Specific Heat Around the $\delta-\varepsilon$ Transition, J. Alloys Compd., 1995, 231, p 78-84.

18. M.S. Anzorena, A.A. Bertolo, L. Gagetti, P.A. Gaviola, M.F. del Grosso, and A.J. Kreiner, Damage Evaluation of Proton Irradiated Titanium Deuteride Thin Films to be Used as Neutron Production Targets, Appl. Surf. Sci., 2018, 443, p 68-73.

19. C. Monnin, P. Bach, P.A. Tulle, M. van Rompay, and A. Ballanger, Optimisation of the Manufacturing Process of Tritide and Deuteride Targets Used for Neutron Production, Nucl. Inst. Methods Phys. Res. A, 2002, 480, p 214-222.

20. S. Yamanaka, T. Tanaka, S. Tsuboi, and M. Miyake, Effect of Oxygen on Solubility of Hydrogen Isotopes in Titanium, Fusion Eng. Des., 1989, 10, p 303-308.

21. S.A. Steward, Isotope Effects in Solutions of Hydrogen and Deuterium in Niobium, J. Chem. Phys., 1975, 63, p 975.

22. D. Prando, A. Brenna, M.V. Diamanti, S. Beretta, F. Bolzoni, M. Ormellese, and M.P. Pedeferri, Corrosion of Titanium: Part 2: Aggressive Environments and Main Forms of Degradation, J. Appl. Biomater. Funct. Mater, 2017, 15(4), p 3-13.

23. P. Cools, N. De Geyter, E. Vanderleyden, P. Dubruel, and R. Morent, Surface Analysis of Titanium Cleaning and Activation Processes: Nonthermal Plasma Versus Other Techniques, Plasma Chem Plasma Process, 2014, 34, p 917-932.

24. G. Wang, J. Li, K. Lv, W. Zhang, X. Ding, G. Yang, X. Liu, and X. Jiang, Surface Thermal Oxidation on Titanium Implants to Enhance Osteogenic Activity and In Vivo Osseointegration, Sci. Rep., 2016, 6, p 31769 .
25. A. Pozio and S. Tosti, Pd-Ag Electrical Resistivity in Hydrogen and Deuterium: Temperature Effect, Materials, 2019, 12(21), p 3551.

26. P. Tripodi, M.C.H. McKubre, F.L. Tanzella, P.A. Honnor, D. Di Gioacchino, F. Celani, and V. Violante, Temperature Coefficient of Resistivity at Compositions Approaching PdH, Phys. Lett. A, 2000, 276, p 122-126.

27. C.T. Liu and J.O. Stiegler, ASM Handbook, Volume 2-Properties and Selection: Nonferrous Alloys and Special-Purpose Materials, 10th ed. ASM International, Metals Park, 1990, p 714-716

28. Y. Fovet, J.Y. Gal, and F. Toumelin-Chemla, Influence of $\mathrm{pH}$ and Fluoride Concentration on Titanium Passivating Layer: Stability of Titanium Dioxide, Talanta, 2001, 53, p 1053-1063.

29. S.L. Ames and A.D. McQuillan, The Effect of Addition Elements on the Electrical Resistivity of $\alpha$-Titanium, Acta Met., 1956, 4, p 619-626.

30. A. Pozio, Z. Jovanovic, R. Lo Presti, M. De Francesco, and S. Tosti, Pd-Ag Hydrogen Content and Electrical Resistivity: Temperature and Pressure Effect, Int. J. Hydrog. Energy, 2012, 37, p 7925-7933.

31. M. Ito, D. Setoyama, J. Matsunaga, H. Muta, K. Kurosaki, M. Uno, and S. Yamanaka, Electrical and Thermal Properties of Titanium Hydrides, J. Alloys Compd., 2006, 420, p 25-28.

32. H.K. Yakel, Thermocrystallography of Higher Hydrides of Titanium and Zirconium, Acta Crystallogr., 1958, 11, p 46-51

33. R.L. Crane, S.C. Chattoraj, and M.B. Strope, A Room-Temperature Polymorphic Transition of Titanium Hydride, J. Less-Common Met., 1971, 25, p 225-227.

34. R. Sailer, G. McCarthy, ICDD Grant-in-Aid. North Dakota State University, 1993, JCPDS code 44-1294 (Ti)

35. M. Gupta, Electronically Driven Tetragonal Distortion in $\mathrm{TiH}_{2}$, Solid State Commun., 1979, 29, p 47-51.

36. L.I. Krishtalik, Kinetic Isotope Effect in the Hydrogen Evolution Reaction, Electrochim. Acta, 2001, 46, p 2949-2960.

Publisher's Note Springer Nature remains neutral with regard to jurisdictional claims in published maps and institutional affiliations. 